\title{
COLECCION CATEDRAS
}

\author{
Facultad de Filosofía y Letras \\ Universidad Nacional Autónoma de México
}

\section{ALFREDO A. ROGGIANO \\ PEDRO IIENRIQUEZ UREÑA EN MEXICO}

Pedro Henrlquez Ureña en México es una obra fundamental surgida de la dedicación, el paciente estudio y el afecto. Alfredo Roggiano ha reunido en clla los testimonios, documentos y artículos - en su gran mayoría inéditos- que le permiten componer la vida cullural del gran escritor dominicano y valorar el impacto de su excepcional magisterio y obra crítica en nuestro país. Dividida en dos clapas, traza con minuciosidad las actividades, relaciones literarias y evolución de ideas que don Pedro tuvo en los días alcióneos de su estadía mexicana. EI lapso que corre entre 1906 y 1914 aborda los momentos estelares de Savia Moderna, la Revisla Moderna y el Alenco de la Juventud: los años, casi míticos, en que un gru po de jovenes escritores renovó por completo la práctica de la filosofía, la literatura y la crítica cultural de México. En una segunda etapa, la de 1921 a 1923, Roggiano resalta la actividad de don Pedro en los tiempos de la cruzada cultural de Vasconcelos: los días del descubrimiento de los valores culturales mexicanos, del establecimiento de la Universidad Obnera y de la Escuela de Verano.

Alfredo Roggiano, poeta y ensayista argentino, es profesor cmérito de la Universidad de Pittsburg. Es, además, el director ejecutivo del Instituto Internacional de Literatura T̈beroamericana. Ocupó la Cáledra Pedro Henrtquez Ureña de la Facultad de Filosofía y Letras de la Universidad Nacional Autónoma de México.

Con esta obra, el profesor Roggiano aporta una pieza relevante y necesaria al cuadro de la cultura mexicana contemporánca.

\section{Los pedidos deben dirigirse a}

\section{ERIKA BRAGA}

\section{C.L. UNIVERSIDAD DE PITTSBURGH, PA 15260}

Precio: US\$12.00. Los cheques deben ser extendidos a favor del INSTITUTO INTERNACIONAL DE LITERATURA IBEROAMERICANA (IILI). El gasto de franqueo está incluido en el precio indicado. Los envíos son por vía regular, superficie en caso de países latinoamericanos o de Europa. 

Por razones ajenas a nuestra voluntad, no se publican antuncios publicitarioss.

Pedimos excusas a nuestros corresponsales de canje.

Mlasta nuevo aviso. 
